\title{
Female mice with a lower prepulse inhibition present higher effects of an early stress on depressive-like behaviour
}

\author{
M.C. Arenas ${ }^{1}$, M.D. Reguilón ${ }^{1}$, M.C. Blanco-Gandía², I. Pérez-Esteban¹, A. Martín-Sánchez³, A. Castro-Zavala ${ }^{3}$, \\ O. Valverde ${ }^{3}$, C. Manzanedo'. \\ ${ }^{1}$ University of Valencia, Psychobiology, Valencia, Spain. ${ }^{2}$ University of Zaragoza, Psychology and Sociology, \\ Teruel, Spain. ${ }^{3}$ University of Pompeu Fabra, Experimental and Health Sciences, B arcelona, Spain.
}

\section{Background:}

The PPI is an operational measure of sensory-motor gating that can identify alterations in the mesolimbic dopaminergic system. Maternal separation with early weaning (MSEW) is a reliable animal model of childhood adversity and depressivelike behaviour. The splash test is used to measure aspects of depression, but preclinical studies have been performed mainly on male subjects, despite women presenting a higher prevalence of depression and being more vulnerable to the negative consequences of stress.

\section{Materials and Methods:}

Female CD1 mice that underwent MSEW or a standard nest (SN) environment were distributed according to their high or low PPI levels. Afterwards, they were assessed in the splash test, which consisted of spraying a $10 \%$ sucrose solution on the dorsal coat of mice.
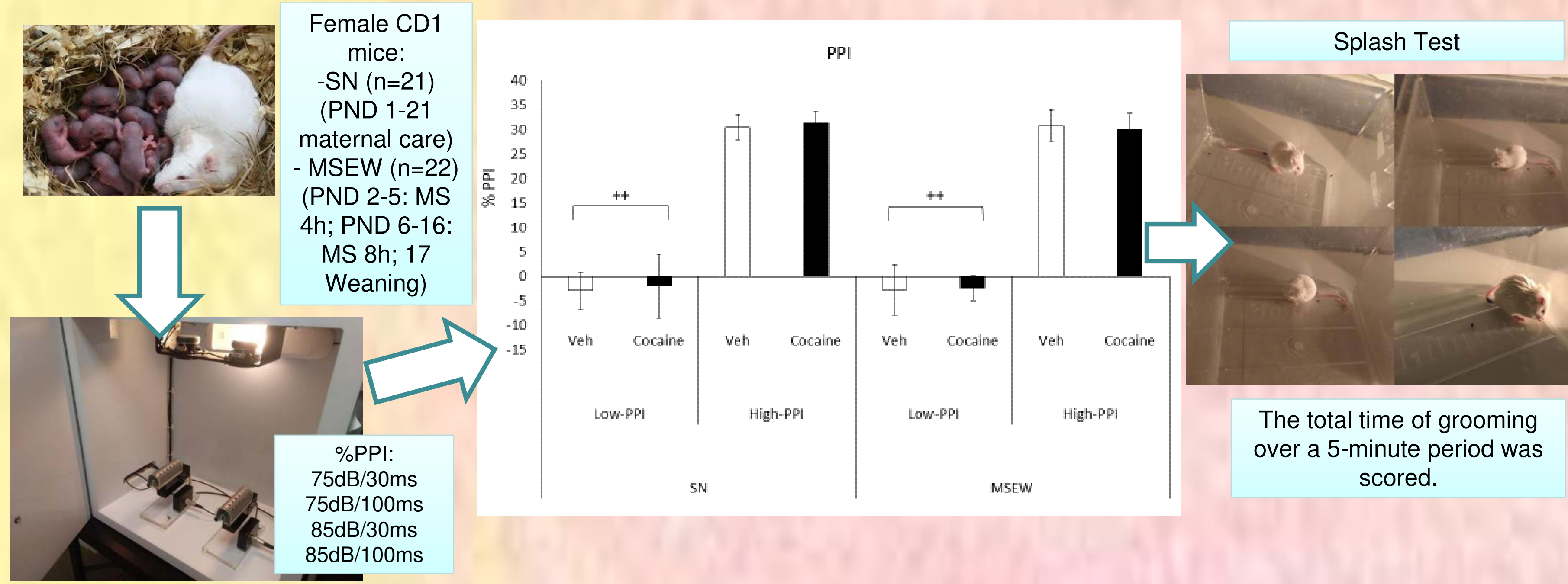

Results:

Total grooming

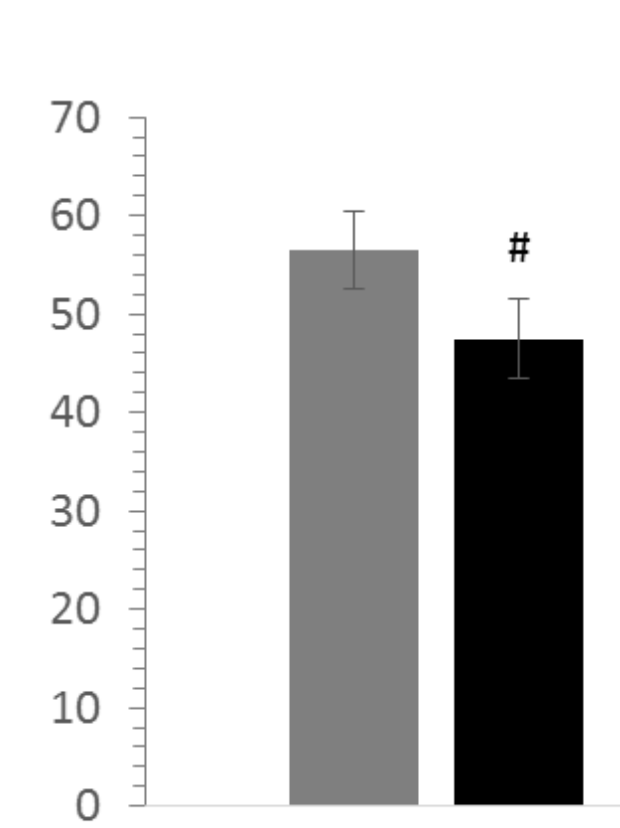

Low-PPI

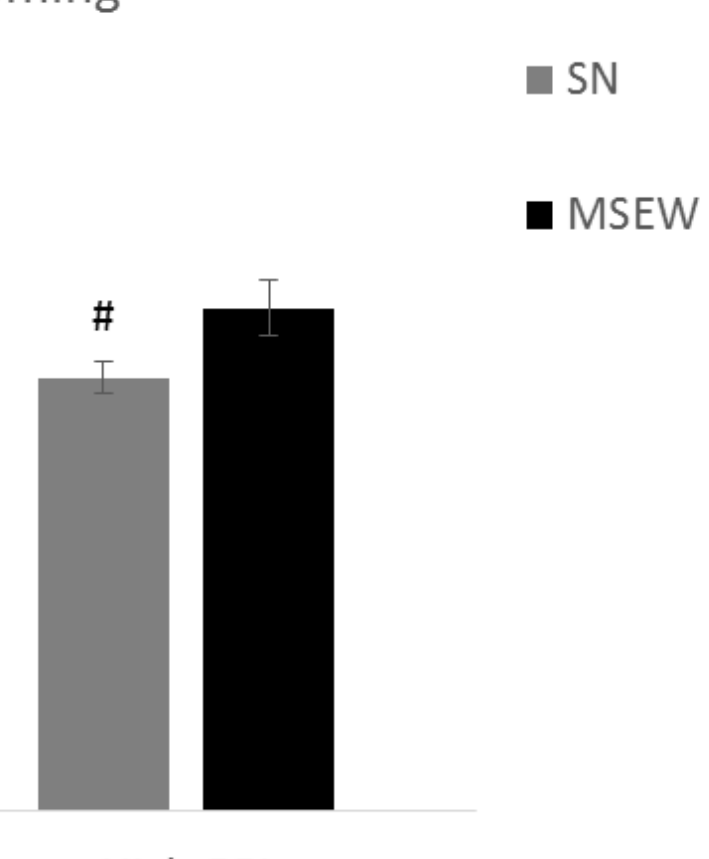

High-PPI

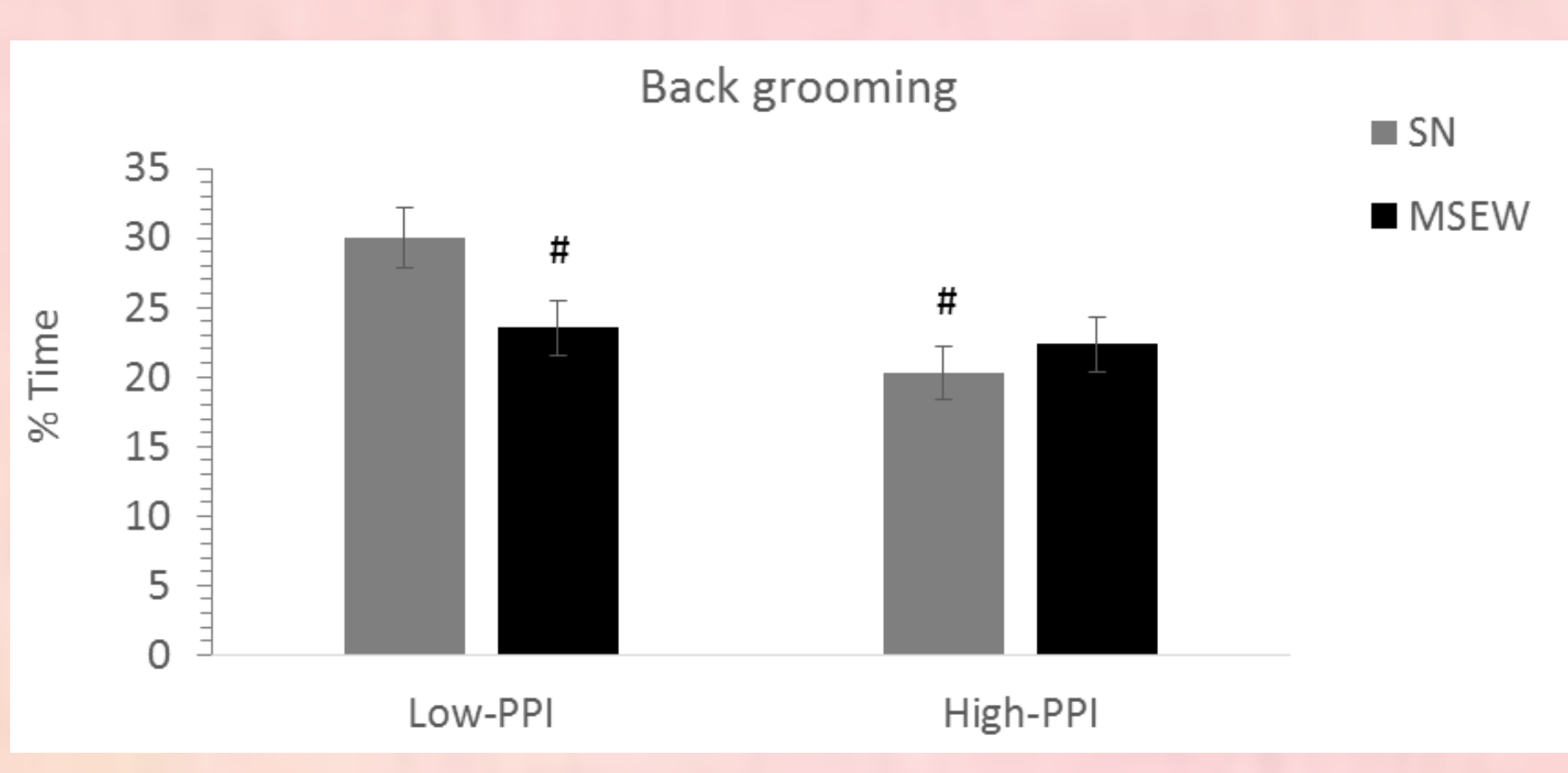

$\# p<0.01$ vs. SN Low-PPI females

\section{Conclusions:}

SN Low-PPI females presented a higher percentage of total and back grooming than SN High-PPI mice and MSEW LowPPI females; however, there was no difference in the percentage of leg grooming. In conclusion, Low-PPI female mice showed higher consequences of MSEW on depressive-like behaviour, since MSEW only decreased the time of back grooming in them. Therefore, PPI levels can identify the more vulnerable animals to an early stress. 